\title{
Educação Ambiental nos anos iniciais do ensino fundamental: várias formas de trabalhar os seus temas
}

\author{
Adriana Tourinho Salamoni ${ }^{1}$, André Nunes Maduell ${ }^{2}$, Dienifer Irigaray Silveira ${ }^{3}$, Letícia Hanna dos

\section{Santos Falcão 4}

\begin{abstract}
Resumo: O modelo atual de desenvolvimento econômico vem utilizando os recursos naturais além de suas capacidades, sem se preocupar com as gerações futuras. Assim, é indispensável a adoção de um novo modelo de crescimento, ressaltando a importância da sustentabilidade associada à qualidade de vida. Considerando a importância da temática ambiental e a visão integrada do mundo, sobressaem-se as escolas, como espaços privilegiados na implementação das atividades de conscientização. Com o objetivo de incentivar a extensão universitária e trabalhar a educação ambiental em escolas do município de São Lourenço do Sul, foi desenvolvido um trabalho piloto numa escola municipal, a fim de construirmos uma metodologia de trabalho em educação ambiental no ensino fundamental. As atividades realizadas na escola consistiram de rodas de conversa, jogos, brincadeiras, apresentação de vídeos, desenhos e atividades práticas. Foram realizadas com alunos das séries iniciais e desenvolvidas atividades de conscientização, a partir da conceituação de temas relacionados ao meio ambiente, rodas de conversas, brincadeiras, jogos e atividades práticas. O trabalho teve uma ótima aceitação pela direção e professores da escola e os alunos sempre se mostraram disponíveis, interessados e receptivos às atividades propostas. 0 projeto mostrou a possibilidade de se desenvolver atividades de extensão em escolas municipais contando com a participação da comunidade acadêmica. Foi importante adequarmos as formas de trabalho à idade dos alunos e, também, realizar uma discussão inicial, conceituando os temas, antes de aplicar jogos, brincadeiras e atividades práticas, tornando o lúdico parte chave do processo de aprendizagem.
\end{abstract}

Palavras-chave: Conscientização; Escola; Processo de Aprendizagem; Sustentabilidade

\section{Environmental education in the early grades of elementary school: several ways of working its topics}

Abstract: The current economic development model has been using natural resources beyond its capabilities without considering future generations. Therefore, it is essential to adopt a new growth model that emphasizes the importance of sustainability associated with quality of life. Considering the importance of the environmental theme and the integrated vision of the world, it becomes clear how important schools are as a space to implement activities to bring awareness about this topic. To encourage university extension and working on environmental education in the schools of São Lourenço do Sul town (Rio Grande Sul State, Brazil), a pilot project was created to develop a methodology of environmental work for elementary grades in municipal schools of São Lourenço do Sul. The activities accomplished within the schools consisted of conversation circles, games and plays, presentations of videos, drawings, and practical activities. This pilot project was welcomed by the school's principal and teachers, as well as the students who were always interested and available to learn about the proposed activities. This project showed that it is possible to develop extension activities in the municipal schools involving the university community participation. It was important to adapt the ways of working to the age of the students and also conduct an initial discussion conceptualizing the themes before working through games and plays, practical activities, making playful part of the learning process.

Keywords: Awareness; School; Learning Process; Sustainability

\author{
Originais recebidos em \\ 10 de julho de 2020 \\ Aceito para publicação em \\ 03 de março de 2021
}

1

Docente da Universidade Federal do Rio Grande - FURG (Campus São Lourenço do Sul).

atsalamoni@furg.br

(autora para correspondência)

2

Graduando em Agroecologia da Universidade Federal do Rio Grande FURG (Campus São Lourenço do Sul). andrenunesmaduell@gmail.com

3

Graduanda em Agroecologia da Universidade Federal do Rio Grande FURG (Campus São Lourenço do Sul).

irigaraydieni@gmail.com

4

Graduanda em Agroecologia da Universidade Federal do Rio Grande FURG (Campus São Lourenço do Sul). leticiahannafalcao@gmail.com 


\section{Introdução}

O Brasil apresenta uma enorme biodiversidade, porém tem sido um grande usuário de produtos químicos, prejudiciais ao meio ambiente, além do uso intensivo das terras, em especial com a monocultura, o que gera impactos ambientais, que serão visíveis por muitas gerações. A problemática ambiental ganha espaço a cada dia na forma de produção de poluição, miséria, fome, doenças, êxodo rural, extinção de espécies e desmatamento, levando a enormes gastos com a indústria farmacêutica e agroquímica, devido ao uso massivo de agrotóxicos, fertilizantes e remédios, além da queda da qualidade de vida. Segundo Pereira e Curi (2012), a problemática ambiental veio se agravando a partir da década de 80 e, com o passar do tempo, surgiram vários movimentos e organizações em defesa da preservação do meio ambiente e da manutenção da vida. Este meio ambiente, com sua dinâmica e constante transformação, pode ser alterado para melhor, trazendo benefícios aos seres que nele vivem, como pode ser piorado, provocando a destruição desses mesmos seres.

A busca da sociedade por um grande desenvolvimento econômico tem utilizado os recursos naturais além das suas capacidades, sem se preocupar com as próximas gerações. Assim, é indispensável a adoção de um novo modelo de crescimento, ressaltando a importância da sustentabilidade, associada à qualidade de vida, pois os recursos não são inesgotáveis. Tampouco a terra conseguirá absorver todos os agroquímicos utilizados e lançados ao meio ambiente pelo ser humano. Cavalcanti (2011) descreveu a sustentabilidade como "uma relação entre sistemas sociais, econômicos e ecológicos, orientados de forma que haja evolução da vida humana, desenvolvimento das culturas, e que os efeitos das atividades humanas permaneçam dentro de limites, que impeçam a destruição da biodiversidade e da complexidade do contexto ambiental".

Cada cidadão deve buscar uma melhor qualidade de vida, mudando atitudes em relação ao "habitat" em que vive, mas sempre buscando sua conservação. Deve, também, reconhecer-se como parte integrante do meio ambiente. Uma das estratégias para a solução dos problemas ambientais passa pela educação dos indivíduos, a fim de que haja o uso mais equilibrado dos recursos (Dias, 2003; Sato, 2003). Calleja (2008) identificou, a partir do estudo de diversos autores, várias definições para a educação. Entretanto, um dos pontos em comum nas diferentes definições de educação foi o de se colocar o indivíduo como sujeito no centro da atividade, sendo este o protagonista. Além disso, a educação foi caracterizada como um processo no qual as pessoas são influenciadas e, assim, são despertadas a uma transformação, capacitando-as para interagir com o meio.

Para Jacobi (2003), com o crescimento da consciência ambiental numa população, esta participará da tomada de decisões em defesa da qualidade de vida, tornando-se corresponsável na fiscalização e no controle dos agentes de degradação ambiental. Segundo o autor, este processo representa um aprendizado social, que se baseia no diálogo e na interação, e que pode se originar na escola. Dessa forma, a escola pode transformar-se no espaço em que o aluno terá condições de analisar a natureza, em um contexto entrelaçado e interdisciplinar de práticas sociais. Dizem Aragão e Dutra (2017) que "a escola, em sua função de realizar a educação e contribuir para a formação de cidadãos, constitui-se num espaço chave para o desafio da educação ambiental, contribuindo para a mudança de comportamento frente à vida". Calleja (2008) também enfatizou que a influência educativa escolar, em qualquer sociedade, é muito significativa.

Para Narcizo (2009), ações urgentes devem ser empreendidas, a fim de minimizar os efeitos das agressões provocadas pelo homem à natureza. Os resultados dessas ações devem trazer benefícios globais, mas elas podem ser iniciadas e desenvolvidas localmente. Um dos caminhos adotados para minimizar os efeitos dessa crise mundial é dirigido à responsabilidade da educação ambiental. Mas o que é educação ambiental?

Segundo a UNESCO (Organização das Nações Unidas para Educação, Ciência e Cultura, 2005) "Educação ambiental é uma disciplina bem estabelecida que enfatiza a relação dos homens com o ambiente natural, as 
formas de conservá-lo, preservá-lo e de administrar seus recursos adequadamente". Para Abreu e Rodrigues (2013), a educação ambiental é de extrema importância no currículo escolar, pois é o caminho para uma nova percepção dos problemas ambientais, funcionando como um meio para conscientizar os alunos, desde tenra idade, a fim de superar os efeitos do uso indiscriminado dos recursos naturais e melhorar a qualidade de vida no planeta.

Segundo Jacobi (2003), a educação ambiental abre um espaço para repensar as práticas sociais. É na escola que os alunos irão adquirir a base adequada para compreender o meio ambiente, a interdependência dos problemas e soluções, e a importância da responsabilidade de cada um para construir uma sociedade mais equitativa e ambientalmente sustentável. A educação ambiental assume, cada vez mais, uma função transformadora, corresponsabilizando os indivíduos na promoção do desenvolvimento sustentável. Diante dos problemas ambientais do mundo, Cuba (2010) enfatiza a importância de que as novas gerações tenham em seus currículos escolares a dimensão ambiental, porque a escola é o lugar ideal para que esse processo seja construído.

A Constituição Federal do Brasil de 1988, no artigo 225, inciso VI, determina que ao poder público cabe "promover a educação ambiental em todos os níveis de ensino e a conscientização pública para a preservação do meio ambiente". Cuba (2010) propõe que a educação ambiental deixe de ser um tema transversal nas escolas e passe a ser uma disciplina separada, dando-se importância maior ao tema. Para o autor, o crescimento e a difusão da educação ambiental são extremamente importantes para que possamos oferecer melhores condições de vida às futuras gerações. Abreu e Rodrigues (2013) investigaram quatro escolas públicas em Uruçuí-PI: três abordavam a educação ambiental de forma interdisciplinar e uma, em disciplinas consideradas afins, como biologia, geografia, física e química. Nas escolas privadas, duas abordavam a educação ambiental de forma interdisciplinar e uma, nas disciplinas afins. Em todas as escolas foi relatado que os projetos de conscientização ambiental envolveram diretamente os alunos. Fragoso e Nascimento (2018) fizeram uma pesquisa na Escola Estadual Cândido Mariano, em Aquidauana/MS. Todos os professores do ensino fundamental II relataram que a educação ambiental é trabalhada de maneira inter, multi e transdisciplinar, em projetos extracurriculares de ciências e geografia, e em projetos nas aulas de ciências, que tratam de assuntos como água, ar, solo e meio ambiente.

Andrade e Talamoni (2013) observaram que alguns projetos de educação ambiental, desenvolvidos em escolas municipais de Brotas/SP, abordavam como temática a preservação do meio ambiente, a conscientização e a promoção de mudanças de hábitos, o tratamento da água, a poluição e o descarte correto do lixo. Esse último é o tema mais citado pelas escolas. Bosa e Tesser (2014) relataram inúmeros desafios na hora de se trabalhar a educação ambiental em escolas no município de Caçador/SC, que vão desde a interpretação do seu significado, até problemas de infraestrutura das escolas e capacitação dos docentes. Como conclusão dos autores, o trabalho de ensinar educação ambiental requer muito conhecimento, persistência e a procura constante de atividades dinâmicas, a fim de consolidar uma educação de qualidade, despertando a consciência ambiental nos alunos. É necessário um novo olhar humanístico para que mudanças ocorram.

Os municípios que possuem representação das universidades estão, permanentemente, desfrutando de um acentuado processo de transformação política, científica, econômica, cultural e social. Esta transformação é incrementada por parcerias firmadas entre as instituições e a comunidade, fomentando a troca de informações e todos os níveis de interação, visto que a universidade tem suas ações objetivadas nos eixos de ensino, pesquisa e extensão, e cumprirá sua finalidade quando houver a indissociabilidade entre estes três eixos. Baumgarten et al. (2017) reforçam que a universidade tem o compromisso de contribuir com as comunidades externas à academia, principalmente aquelas que carecem de suporte e informações técnicas e científicas.

O Campus da FURG em São Lourenço do Sul tem cursos voltados à sustentabilidade, então, com o objetivo de 
incentivar a extensão universitária e aplicar a educação ambiental em escolas do município, foi desenvolvido um trabalho piloto numa escola do município, com vistas a construir uma metodologia de trabalho em educação ambiental no ensino fundamental.

\section{Metodologia}

O trabalho foi desenvolvido de junho de 2017 a dezembro de 2019, na Escola Municipal de Ensino Fundamental (E.M.E.F.) Professora Izolina Passos, localizada na Rua Teodoro Porepp, 663, no bairro Nova Esperança, no município de São Lourenço do Sul, estado do Rio Grande do Sul. As atividades foram realizadas com os alunos das séries iniciais $\left(1^{\circ}, 2^{\circ}\right.$ e $3^{\circ}$ ano), com faixa etária entre 6 e 12 anos. Em cada ano de desenvolvimento das atividades participaram cerca de 45 alunos e 3 professores, distribuídos nas 3 séries trabalhadas, além da participação ativa da vice-diretora da escola, à época.

\section{Desenvolvimento}

Para o desenvolvimento das atividades, foram definidas como etapas:

1) a partir de consulta à bibliografia e de discussões entre os integrantes do projeto, foram realizadas reuniões para a construção dos conteúdos, brincadeiras e oficinas. As possibilidades de adaptação dos conteúdos às diferentes séries trabalhadas também foram estudadas;

2) foi conduzida uma reunião com a direção e professores da escola para expor as atividades a serem desenvolvidas e coletar sugestões;

3) aplicação das atividades e documentação das mesmas;

4) análise das atividades desenvolvidas (Figura 1).

A dinâmica de atuação deste projeto consistia em atividades direcionadas à conservação e preservação da natureza, em que foram abordados assuntos relacionados ao meio ambiente, tais como: princípios da agroecologia, importância da água, do ar e do solo, poluição, alimentação saudável, importância e papel dos animais no ambiente, insetos polinizadores, importância das abelhas na agricultura, problemas causados pelo uso de agrotóxicos, separação e reciclagem do lixo e compostagem. A escolha dos temas teve como princípio a área de atuação da docente responsável pelo projeto, a área de formação dos acadêmicos e o nível de escolaridade das crianças.

O trabalho com os alunos do $1^{\circ}, 2^{\circ}$ e $3^{\circ}$ ano foi desenvolvido separadamente, por sala de aula, e iniciava a partir de uma conversa com os alunos a respeito do meio ambiente (ecossistemas, biodiversidade, sistemas de produção de alimentos, hortas, produção de mudas, sementes crioulas, ciclagem de nutrientes e teia trófica, manejo e interações ecológicas, água, solo, poluição, vegetação, reciclagem, lixo) e sobre Agroecologia.

Os temas eram apresentados na forma de debate com os alunos, com conceituação, apresentação de filmes, desenhos e atividades, como confecção de cartazes, desenhos, jogos e brincadeiras. Os alunos tiveram contato com algumas das práticas da agroecologia através de explanações dinâmicas e também de filmes de animação que tocam no assunto. 


\section{Metodologia de trabalho em \\ Educação Ambiental na E.M.E.F. Professora Izolina Passos}

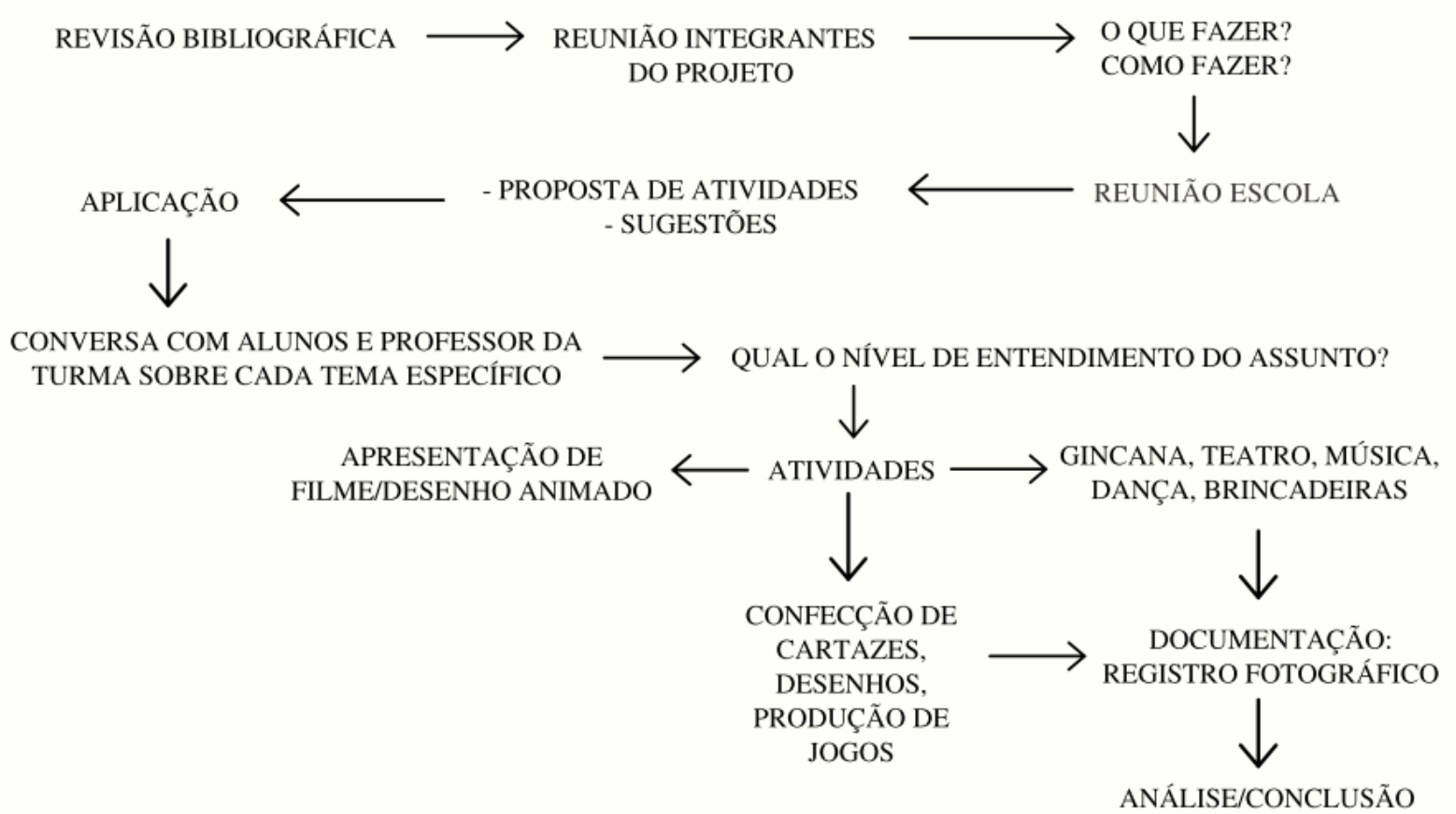

Figura 1. Fluxograma da metodologia de trabalho em Educação Ambiental na E.M.E.F. Professora Izolina Passos (São Lourenço do Sul, 2017-2019).

\section{Relato de experiência}

Tema: lixo

Sobre este tema foi apresentado o episódio "Lixo e Desperdício", desenho animado da coleção "Natureza Sabe Tudo", disponível no Youtube. Após a apresentação, realizamos uma roda de conversa com os alunos, trocando impressões sobre a mensagem do desenho, avaliando o nível de entendimento e compreensão e, também, sua relação com o assunto (Figura 2a).

Após a discussão inicial sobre o tema, as crianças foram separadas em grupos e, na forma empírica, estimuladas a separar o lixo, discutindo entre si onde cada lixo deveria ser colocado (Figura 2b,c).

Os materiais foram classificados como vidro, metal, plástico, tetrapak, não recicláveis e orgânicos. Ao término da brincadeira, foi feita uma discussão sobre a separação correta do lixo e uma verificação da separação feita pelas crianças. A proposta para finalizar o conteúdo foi de que as crianças realizassem desenhos sobre "família, natureza e o lixo", demonstrando em seus desenhos como viam ou viviam essa temática em suas vidas e, por fim, interpretando para os colegas suas representações.

Observou-se nesta atividade que, quanto maior a idade das crianças, mais fácil foi o entendimento sobre as problematizações que envolvem o lixo: o que é? Quais os destinos? A compreensão da atividade foi facilitada porque a escola está localizada num bairro do município que conta com uma associação forte de recicladores. 

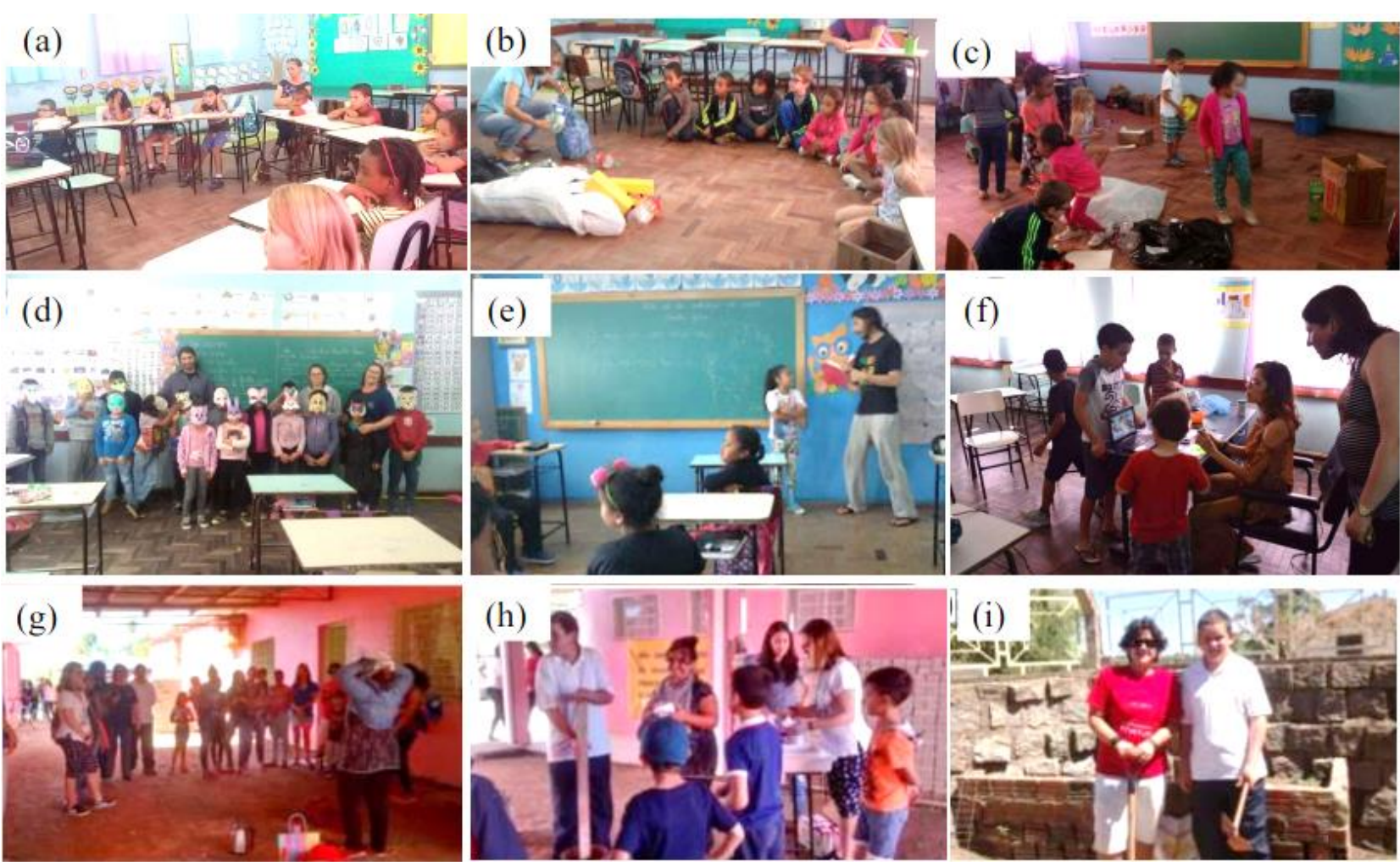

Figura 2. Atividades de Educação Ambiental desenvolvidas pelos alunos do ensino fundamental da E.M.E.F. Professora Izolina Passos: a) roda de conversa sobre lixo; b, c) separação do lixo; d, e) atividade sobre cadeia alimentar; f) conhecendo os animais; $g$, h) produção de sabão no dia da cidadania; i) compostagem no dia da cidadania (São Lourenço do Sul, 2017-2019).

Por isso, muitos já praticam várias atividades de separação do lixo, nas suas residências. Também ficou evidente, que quanto mais cedo o tema é abordado, mais fácil a compreensão do assunto e a possibilidade de colocar em prática atitudes sustentáveis. A compreensão também é facilitada quando as crianças transportam para o seu dia a dia o uso de materiais reciclados, transformando-os, especialmente em brinquedos. Trazemos, neste momento, um item atual e incisivo na educação moderna através de Antunes (2001), que trata da significatividade dos conteúdos para melhor entendimento e aproveitamento do aluno.

\section{Tema: cadeia alimentar}

Num primeiro momento, foi feita uma roda de conversa com os alunos a fim de discutir cadeia alimentar e categoria trófica, e obter sua visão sobre o assunto. Posteriormente, foram apresentados vídeos sobre o tema: Cineminha das Abelhas (da Confederação Brasileira de Apicultura), O que é Cadeia Alimentar (de vídeos educativos para crianças) e Cadeia Alimentar (da Editora Sei), e foi feita uma nova roda de conversa. Em continuidade à atividade, os alunos foram orientados a confeccionar máscaras representando um animal, à sua escolha, e apresentar aos colegas (Figura 2d).

Com as máscaras confeccionadas e com o conhecimento adquirido nos encontros anteriores, os alunos, em seus grupos de trabalho, organizaram uma série de possíveis cadeias tróficas. Depois de organizá-las, fizeram um teatro sobre estas cadeias, utilizando suas máscaras e incorporando o personagem do animal escolhido. A partir do conhecimento teórico, os alunos fizeram a brincadeira "que bicho sou eu, categoria trófica". Nesta brincadeira os alunos escolhiam um animal e contavam a escolha feita apenas para um dos integrantes do 
grupo de trabalho. Após a escolha, o aluno dava características do animal começando pela categoria trófica, classe e depois características físicas do animal. A cada dica dada, na forma de descrição verbal, os colegas tentavam adivinhar qual era o animal escolhido (Figura 2e).

O trabalho com este tema foi organizado e planejado para várias semanas. Observou-se com o passar do tempo que as crianças foram facilmente incorporando informações técnicas sobre produtores e consumidores. Acredita-se que a compreensão foi facilitada pela variedade de atividades desenvolvidas, além de que as mesmas foram realizadas de forma calma e lúdica.

\section{Tema: conhecendo os animais}

Foi realizada uma atividade usando microscópio estereoscópico. Os alunos foram incentivados a observar a morfologia de alguns insetos, como abelhas e aranhas, suas adaptações em relação ao meio ambiente, e relacioná-los às suas funções e tipos de alimentos consumidos (Figura 2f). Também foram apresentadas estruturas de plantas, como estômatos e tricomas, mostrando a importância e funções na planta. Mesmo sendo observações microscópicas, em que muitas vezes até os mais velhos não têm a percepção das observações, as crianças mostraram-se bastante interessadas. Entretanto, percebeu-se que é uma atividade que não prende muito a atenção dos menores, decaindo o nível de participação e interesse.

\section{Tema: hortas urbanas - planta, água, solo e Agroecologia}

Foi feita uma discussão inicial com os alunos, a partir de conhecimentos básicos de temas relacionados à água, solo e plantas. Esta atividade foi realizada em sala de aula, estudando através de poemas, textos e exercícios simples, começando pelos órgãos das plantas e suas respectivas funções. A atividade foi feita na forma de uma roda de conversa, com música. Todas as atividades relacionadas às hortas foram se desenvolvendo com base na observação de como os estudantes demonstravam suas necessidades e interesse nos assuntos em torno do tema. Os alunos foram colocados em contato com várias plantas medicinais, como alecrim, lavanda, orégano, tomilho, hortelã e manjericão.

Este tema foi abordado de forma leve, com atividades de alongamento antes do seu início. Após o conhecimento inicial do tema, os estudantes receberam um bilhete destinado aos pais, solicitando doação de garrafas pet para produção de mudas. No encontro seguinte, todos os estudantes trouxeram suas garrafas e procedeu-se o plantio das mudas em uma horta disponível na escola. Além do plantio, cada dupla fez o reconhecimento da sua planta, conhecendo seu nome, cheiro e textura. A montagem das mudas possibilitou trabalhar os diferentes tipos de solo ali apresentados, algumas características e funções. Para conhecer melhor as plantas medicinais, os alunos foram incentivados a montar um quebra-cabeça relacionando fotos e nomes das plantas medicinais. Além disso, junto com duas jovens da Caravana da Juventude Rural, foram feitas diversas atividades lúdicas, com danças, músicas e jogos, trabalhando o tema semente. Para finalizar este tema, foi explorada a água - sua formação, características e importância na manutenção da vida. A atividade foi finalizada com a música "Água" da banda "Palavra Cantada", disponível no Youtube.

A partir do trabalho com as plantas e sementes, os alunos assistiram ao vídeo "Comida que alimenta" e "Agroecologia é vida", com a temática da agroecologia, procedendo-se uma discussão do tema. Estes vídeos foram realizados pelo Centro de Desenvolvimento Agroecológico Sabiá, vinculado ao projeto Trabalho, Renda e Sustentabilidade no Campo, patrocinado pela Petrobrás, e disponível no Youtube. Sobre as práticas de agroecologia, discutiu-se com os alunos as agroflorestas, a produção livre de agrotóxicos, a compostagem, o consumo de frutas e verduras da época, a importância da agricultura familiar, além de reforçar os assuntos já abordados sobre conservação do solo e da água.

Mesmo não tendo conhecimentos técnicos sobre germinação e desenvolvimento vegetal, os alunos 
mostraram-se extremamente motivados a produzir suas próprias mudas. A questão do manuseio das plantas, a fim de conhecer seu aroma e sua textura, e a inserção da música na atividade, foram importantes para despertar seu interesse no assunto. Há possibilidade de trabalhar mais este tema no futuro, visto que a escola possui uma área destinada à compostagem e usa temperos e chás, no seu refeitório, de produção própria.

\section{Dia da cidadania}

A escola realiza todos os anos o "Dia da Cidadania" e que consiste em atividades gratuitas abertas para a comunidade, em que são oferecidos: corte de cabelo e manicure, consultas médicas e exames, dentre outros. Além disso, ocorrem brincadeiras e gincanas para as crianças e atividades esportivas para os adolescentes. As atividades desenvolvidas pelos alunos da FURG consistiram em brincadeiras com as crianças, preparo de sabão (Figuras $2 \mathrm{~g}, \mathrm{~h}$ ) e atividades de compostagem (Figura 2i). Dessa forma, foi possível trabalhar com eles e a comunidade a reutilização de materiais como óleo usado, restos de alimentos e criar alternativas de produção, no espaço urbano.

\section{Discussão}

A construção do pensamento ecológico deve ser inserida desde os anos iniciais de vida, a fim de que se desenvolva uma mentalidade inovadora, voltada à conservação da natureza e enfatizando o consumo de alimentos saudáveis e o uso consciente dos recursos naturais. Neste trabalho, identificou-se a importância de adaptar as atividades à idade dos alunos, desenvolvendo o mesmo tema de formas diferentes, para melhor compreensão e participação de todos. Cuba (2010) já dizia que, para o processo de multiplicação da conscientização ecológica, é vital o trabalho de educação ambiental dentro e fora da escola. Segundo ele, o trabalho deve incluir projetos que envolvam os alunos em sala de aula, tornando-os multiplicadores de atitudes sustentáveis. Segundo o relato de Narcizo (2009), existem muitos obstáculos quando se desenvolvem projetos de Educação Ambiental em escolas. Apesar disso, a autora percebeu que essa ainda é uma das melhores formas de se construir uma nova concepção do tema, e que é importante criar laços afetivos entre a escola e a comunidade, possibilitando, assim, que os problemas ambientais passem a ser de todos.

Neste trabalho, observou-se grande empolgação dos alunos, desde as propostas dentro da sala de aula, especialmente relacionadas aos animais e à cadeia trófica, até ao que era relacionado à criação da horta ou atividades voltadas às plantas, mostrando assim a necessidade de projetos educacionais que aproximem a criança, o conteúdo interdisciplinar na escola, e a prática ambiental. A prática ambiental é fundamental no processo de conscientização socioambiental. Observou-se que ela pode se dar por meio de atividades lúdicas, envolvendo brincadeiras e, também, tornando o aluno sujeito nas atividades, como na compostagem, na semeadura e no cuidado com as mudas. Andrade e Talamoni (2013) observaram que alguns projetos de educação ambiental, que abordavam como temática a preservação do meio ambiente, usaram como atividades a elaboração de textos, cálculos, coleta de dados, registro fotográfico, desenhos, pintura, ecoturismo e oficinas, fazendo dos alunos sujeitos das atividades. Num outro estudo, professores de uma escola pública disseram ser muito importante debater assuntos que tratem do meio ambiente e que possam contribuir na execução de projetos ambientais que despertem o interesse do aluno, para que ele seja um exemplo de cidadão ambiental, que cuida e preserva (Fragoso \& Nascimento, 2018).

Quando se solicitou que os alunos levassem materiais de casa para aprender a separar o lixo e confeccionassem recipientes para a horta, foi muito importante envolver as famílias e fazê-las participar das atividades desenvolvidas na escola. As atividades desenvolvidas no dia da cidadania contaram com a participação de muitos alunos, que se envolveram nas brincadeiras propostas. Entretanto, não houve envolvimento de grande parte da comunidade. Isso pode ter sido atribuído à falta de divulgação nas famílias, falta de interesse nos 
assuntos tratados e/ou a dificuldade de comparecer no dia do evento. Numa proposta de continuidade do projeto, os autores acreditam que será importante realizar uma visita às famílias, a fim de explicar o projeto e incentivá-los a participar do mesmo. Narcizo (2009) já relatava as dificuldades de se desenvolver projetos de educação ambiental em escolas, mas o autor enfatizou a importância de que os projetos envolvam professores e alunos com toda a comunidade.

Apesar do espaço pequeno que a escola possui, foi possível trabalhar os plantios e a compostagem, na área externa. Acredita-se que este espaço, além de possibilitar o trabalho em educação ambiental, possa suprir as necessidades de consumo da escola. Além de fornecer algumas ervas para tempero e chás, poderia também promover a aproximação entre os pais dos alunos e a escola, por exemplo, através da troca de mudas e fornecimento de composto orgânico, criando ciclos solidários. Rodrigues (2018) fez uma breve análise dos trabalhos de educação ambiental em escolas de Santa Catarina. $O$ autor relatou o grande número de atividades envolvendo as temáticas: lixo e hortas escolares, geralmente, a partir da compostagem de resíduos orgânicos gerados na escola, para utilização como fertilizante natural.

Para finalizar, os alunos do curso de Agroecologia se mostraram sempre interessados, envolvidos e parceiros na condução das atividades na escola, mostrando que estes são capacitados a desenvolver trabalhos de educação ambiental com crianças das séries iniciais. A direção da escola e os professores também sempre se apresentaram disponíveis e interessados no projeto, relatando a importância de se continuar a fazer este tipo de atividade. Baumgarten et al. (2017) fizeram um mini-curso para estudantes do ensino fundamental, na Ilha dos Marinheiros, em Rio Grande - RS, e verificaram que o projeto aproximou a universidade da comunidade e ofereceu ações concretas, tanto de experiências vivenciadas, como de conhecimento e empoderamento da comunidade com relação à sua qualidade ambiental.

\section{Conclusão}

A pesquisa e prática empírica mostraram a possibilidade de se desenvolver atividades de extensão voltadas para a temática socioambiental, trabalhando temas como lixo, cadeia alimentar, hortas urbanas, compostagem, água, solo, ar e florestas, por exemplo, com alunos do ensino fundamental, em processo de alfabetização ou já alfabetizados, em escolas municipais, contando com a participação dos estudantes da universidade e supervisionados por um docente da área. Nesse ponto, a universidade cumpre seu papel de atuar junto à comunidade e desafia os acadêmicos a estudar e propor diferentes metodologias de ensino de temas relativos ao meio ambiente.

Na organização de uma metodologia de trabalho, foi importante adaptar o modo de trabalho de cada um dos temas, à idade dos alunos, já que se trabalhou com crianças alfabetizadas e com aquelas em processo de alfabetização. Também foi importante realizar uma discussão inicial conceituando cada tema trabalhado e, após, acrescentar os jogos, brincadeiras e as atividades práticas, tornando o lúdico parte chave do processo de aprendizagem e de conscientização sobre os temas. Atividades dinâmicas e variadas foram primordiais no processo.

Os temas abordados nas salas de aula, também o são pelos professores regentes das turmas visitadas. Acreditase que uma compreensão nova, vinda do meio acadêmico, transmitida por jovens, em linguagem simples, com uma visão voltada à área da sustentabilidade, da agroecologia, dos recursos renováveis, venha somar-se ao conhecimento adquirido de forma clássica na escola. Assim, ganha a escola com a discussão de temas relevantes sobre meio ambiente, discutidos e trabalhados de forma leve e dinâmica, e ganham os universitários quando discutem, trocam ideias e preparam-se para as atividades propostas.

Tendo em vista o retorno positivo da escola e as discussões realizadas pelo grupo envolvido, após as últimas 
atividades, observa-se que este trabalho piloto cumpriu sua proposta de organizar uma metodologia de trabalho em educação ambiental. Entretanto, resta como grande desafio a possibilidade de incluir a comunidade do entorno da escola na proposta já desenvolvida.

\section{Agradecimentos}

Aproveitamos o espaço para agradecer à direção, professores e alunos da Escola Municipal de Ensino Fundamental (E.M.E.F.) Professora Izolina Passos que nos abriram as portas e acreditaram em nosso trabalho. Um agradecimento especial à Diretora Raquel Quevedo e à ex-Diretora Ângela, que nos deixou tão cedo e que nos acolheu no início deste trabalho. À Julhana Pereira Figueiredo, que fez a oficina de compostagem e à Lisandra Files Dias, que preparou a oficina de sabão. À Catarine Baini Verdi, Marina Moreira da Rocha e Gisele Rocha de Araújo e Santos que auxiliaram nas correções e no abstract. Ao pessoal do Campus da FURG, que ajudou na logística para que o trabalho pudesse ser desenvolvido. $E$, finalmente, um agradecimento à Universidade Federal do Rio Grande - FURG pela disponibilização de bolsa de extensão - EPEC.

\section{Contribuição de cada autor}

A autora A.T.S. planejou e coordenou o projeto de extensão, foi orientadora dos alunos na proposta extensionista, fez a revisão crítica do artigo e a redação final; A.N.M. foi bolsista no projeto de extensão e participou de todas as etapas do seu desenvolvimento, desde a metodologia de trabalho até implantação e interpretação da experiência realizada, revisão da literatura e escrita do artigo; D.I.S. participou de todas as etapas do desenvolvimento do projeto, desde a metodologia de trabalho até implantação e interpretação da experiência realizada, revisão da literatura e escrita do artigo; L.H.S.F. participou da etapa referente as hortas urbanas, desde a metodologia de trabalho até a implantação, auxiliou na revisão da literatura e na escrita do artigo.

\section{Referências}

Abreu, G. G. de, \& Rodrigues, M. A. (2013). O tratamento de educação ambiental nas escolas públicas e privadas: Um estudo de caso nas escolas do ensino fundamental da cidade de Uruçuí-PI. Enciclopédia Biosfera, 9(16), 2371-2384.

Andrade, T. Y. I., \& Talamoni, J. L. B. (2013). A educação ambiental nas escolas municipais de Brotas (SP): Análise de concepções e ações no contexto do programa Município Verde Azul. EPEA - Encontro Pesquisa em Educação Ambiental, 7, Rio Claro - SP, 07 a 10 de julho de 2013. Rio Claro: UNESP. Recuperado de http://www.epea.tmp.br/ epea2013 anais/pdfs/plenary/0123-1.pdf

Antunes, C. (2001). Como transformar informações em conhecimento. 5. ed. Petrópolis-RJ: Vozes.

Aragão, P. G. de V., \& Dutra, H. V. G. (2017). Caminhos para a educação ambiental através da extensão e da interdisciplinaridade: a experiência do projeto tema em foco. Ambiente e Educação - Revista de Educação Ambiental, 22(1), 275-292.

Baumgarten, M. G. Z., Pereira, A. L., Rodrigues, H. R. S., Veloso, C., Dias, G., \& Lima, K. (2017). “Vamos conversar sobre a água da ilha dos marinheiros?": Um mini-curso para estudantes do ensino fundamental de uma comunidade sem suprimento de água potável canalizada (Rio Grande/RS). Ambiente e Educação-Revista de Educação Ambiental, 22(2), 262-282.

Bosa, C. R., \& Tesser, H. C. de B. (2014). Desafios da educação ambiental nas escolas municipais do município de Caçador - SC. Revista Monografias Ambientais - REMOA, 14(2), 2996-3010.

Calleja, J. M. R. (2008). Os professores deste século. Algumas reflexões. Revista Institucional Universidad Tecnológica del 
Chocó, 27(1), 109-117.

Cavalcanti, A. P. B. (2011). Sustentabilidade ambiental como perspectiva de desenvolvimento. Revista Internacional Interdisciplinar - INTERthesis, 8(2), 219-237.

Cuba, M. A. (2010). Educação ambiental nas escolas. ECCOM - Revista eletrônica do curso de Comunicação Social, das Faculdades Integradas Teresa D'Ávila (FATEA), 1(2), 23-31.

Dias, G. F. (2003). Educação Ambiental: Princípios e prática. 8. ed. São Paulo: Gaia.

Fragoso, E., \& Nascimento, E. C. M. (2018). A educação ambiental no ensino e na prática escolar da escola estadual Cândido Mariano, Aquidauana/MS. Ambiente e Educação - Revista de Educação Ambiental, 23(1), 161-184.

Jacobi, P. (2003). Educação Ambiental, Cidadania e Sustentabilidade. Cadernos de Pesquisa, 118, 189-205.

Narcizo, K. R. dos S. (2009). Uma análise sobre a importância de trabalhar Educação Ambiental nas escolas. Revista Eletrônica do Mestrado em Educação Ambiental da Universidade Federal do Rio Grande, 22, 86-94.

Pereira, S. S., \& Curi, R. C. (2012). Meio Ambiente, Impacto Ambiental e Desenvolvimento Sustentável: Conceituações Teóricas sobre o Despertar da Consciência Ambiental. Revista de Administração, Contabilidade e Sustentabilidade, 2(4), 35-57.

Rodrigues, J. C. R. (2018). A educação ambiental nas escolas de Santa Catarina. Ambiente e Educação - Revista de Educação Ambiental, 23(1), 140-160.

Sato, M. (2003). Educação Ambiental. São Carlos: Rima.

Organização das Nações Unidas para Educação, Ciência e Cultura (2005). Década das Nações Unidas da Educação para um Desenvolvimento Sustentável, 2005-2014: Documento final do esquema internacional de implementação. Brasília: UNESCO.

Como citar este artigo:

Salamoni, A.T., Maduell, A. N., Silveira, D. I., \& Falcão, L. H. dos S. (2021). Educação Ambiental nos anos iniciais do ensino fundamental: Várias formas de trabalhar os seus temas. Revista Brasileira de Extensão Universitária, 12(1), 65-75. https://periodicos.uffs.edu.br/index.php/RBEU/article/view/11601/pdf 